\title{
DISCUSSÕES SOBRE O CONCEITO DE MEIO AMBIENTE
}

\author{
Manoel Carlos de OLIVEIRA *
}

\begin{abstract}
RESUMO
O conceito de meio ambiente é retomado após trabalhos anteriores do mesmo autor. Aparece como o estudo do espaço e seus componentes visto de uma forma dinâmica em suas múltiplas relações. Para tanto, é analisado através da abordagem de sistemas que é a forma metodológica, mais eficiente para se entender o funcionamento do meio ambiente, como sistema ambiental.
\end{abstract}

\section{ABSTRACT}

The environment concept is taken from former works about this subject, written by the same author. It appears as the study of the space and its components, seen in dynamic way in its various relationships. For this purpose it is analysed through system approach which is the most efficient methodological way to understand the environment working, as the environmental system.

\section{INTRODUÇÃO}

Em trabalho anterior, "A Natureza e o Homem no Estado de São Paulo - Um Panorama" (1976), foi desenvolvido pelo autor um estudo conceitual sobre o meio ambiente, posteriormente complementado no trabalho "Política de Ciência e Tecnologia em Geociências - Aproximação I" (1982). Ambos foram baseados em estudos realizados no campo da Geografia vista como ciência ambiental, em especial na Geologia, utilizando a abordagem de sistema como suporte metodológico à teoria sobre o meio ambiente. Esses trabalhos foram retomados, servindo de embasamento às idéias desenvolvidas no presente estudo que visa mostrar os múltiplos aspectos da questão ambiental. Por outro lado, a participação do autor no movimento ambientalista bem como os inúmeros contatos técnico-científicos advindos dessa participação contribuíram para o aprimoramento das idéias que serão expostas.

Em OLIVEIRA et alii (1976) foi formulado o seguinte conceito: "O meio ambiente é um determinado espaço constituído de componentes que estão relacionados entre si (fig. 1). O conceito expresso em OLIVEIRA et alii (1982) fala do meio ambien- te como sistema e diz: "Este sistema representa o funcionamento do meio ambiente, através da entrada de energia e seu fluxo, criando processos de gênese e evolução através do tempo, delimitados pelo espaço e o ciclo da matéria" (fig. 2).

$\mathrm{O}$ termo meio ambiente tem sido usado nos últimos quinze anos com grande freqüência, refletindo a crise planetária que se tem acentuado nesses últimos anos. Apesar do uso frequiente desse termo, nota-se que as preocupações mais objetivas com o meio ambiente são intermitentes e refletem um posicionamento muito mais mercadológico, o meio ambiente passa a ser um produto de consumo. Nas épocas em que os interesses econômicos se contrapõem aos da preservação do meio ambiente, o termo sofre um processo de depreciação quanto a seu conteúdo, tornando-se apenas uma forma de expressão. Os grupos que poderiam atuar de forma efetiva na defesa do meio ambiente se vêem bloqueados em função do aparecimento de interesses econômicos em jogo.

Os geógrafos sempre tiveram contato com o termo "meio", que representa o arranjo do conjunto de fatores basicamente naturais, formando uma individualidade espacial. O termo "ecúmeno" está associado

* Instituto Geológico - Caixa Postal 8772 - 01000 - São Paulo, SP, Brasil. 


\section{MEIO AMBIENTE - COMPONENTES}


SISTEMA AMBIENTAL

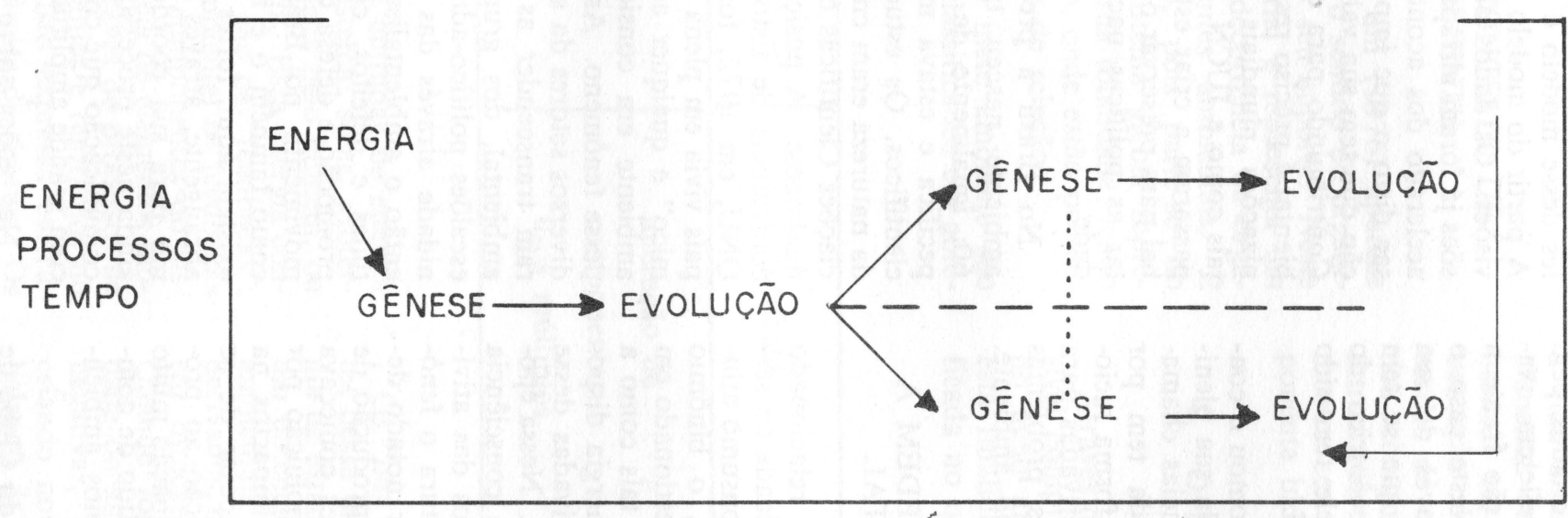

POTENCIAL

DE REICLAGEM

ESPACCO, MATÉRIA

Figura 2 
ao "meio" e aparece como a capacidade do homem de ocupar o espaço apesar das limitações impostas pela natureza. Representa a ação do conjunto dos mecanismos culturais, criados para se proceder à apropriação do espaço.

Ambos os conceitos, apesar das suas aparentes contradições, são complementares, pois o "ecúmeno" depende do "meio", ou seja, os mecanismos culturais criados pelo homem para ocupar o espaço refletem, exatamente, uma capacidade de ação frente a barreiras de ordem natural. Neste caso o "meio" ambiente é visto através de sua organização. Outra discussão que se tem colocado é o caráter antropocêntrico do termo "meio ambiente" pois ele tem sido visto em função do "ecúmeno".

Hoje em dia a Geografia retomou o conceito de meio ambiente em toda sua plenitude, junto com as outras ciências chamadas ambientais. Essa retomada tem por finalidade sistematizar de uma forma racional os estudos e suas ações derivadas para se propor soluções frente aos problemas apresentados pelo uso do meio ambiente.

\section{FATOS QUE ANTECEDEM A QUESTÃO AMBIENTAL}

Grande parte do interesse relacionado ao meio ambiente nasceu na década de sessenta, quando a sociedade de consumo atingia seu auge. Nesse período, o binômio produção/consumo não era questionado em função do que lhes antecedia, tais como a existência de matéria-prima, energia disponível e finita, e as sobras derivadas desse binômio, especificamente o lixo. Nessa época já havia um certo gra'ı de consciência em relação aos impactos diretos das atividades econômicas. $\mathrm{Na}$ agricultura o fenômeno da erosão começou a ser notado devido à diminuição sensível da produção de alimento, e nas grandes cidades começava a ser notado o fenômeno da poluição por estar causando uma série de impactos na saúde de suas populações. Apesar de se notar esta consciência em relação ao problema, esta refletia uma preocupação muito mais setorial que global no sentido de compreender a ação dos mecanismos ambientais e suas várias implicações.

Somente a partir da criação do Clube de Roma (em 1968) e do relatório do MIT, Massachussets Institute of Technology
(1970), foi possível colocar em discussão de maneira eficiente e abrangente a questão ambiental, vista através das grandes preocupações da humanidade (sobreviver, ter qualidade de vida, crescer) em um cenário altamente mutável e limitador. Foi apresentado um modelo global para a percepção do conjunto de problemas da humanidade, baseado na abordagem de sistemas, o que permitia compreender os componentes desse modelo e suas múltiplas relações. A partir do modelo global foram feitas previsões. Os dados obtidos com essas previsões já foram ultrapassados, devido ao ritmo acelerado dos acontecimentos atuais. Apesar disto o que importa é sua fundamentação que tem sua validade ainda assegurada. Contribuindo para enfatizar a questão ambiental é preciso ressaltar o papel das organizações mundiais relacionadas ao setor, tais como a IUCN, UNESCO e outras, que passaram a criar estratégias de caráter global para preservar o meio ambiente e orientar as políticas nacionais para esta finalidade.

No Brasil a preocupação com o meio ambiente nasceu também na década de 60 , igualmente de maneira setorial e específica e estava mais afeita aos círculos científicos. Os estudos e ações na defesa da natureza eram empreendidos pelas Associações Científicas ou por cientistas, individualmente. A posição do Brasil, durante a conferência de Estocolmo, organizada pela ONU, em 1972, foi bastante criticada. O país vivia em plena era do "milagre econômico" e qualquer ação na defesa do meio ambiente era considerada como inibidora desse fenômeno. As críticas levantadas por diversos setores da sociedade brasileira fizeram transcender as discussões da questão ambiental, dos grupos científicos para os escalões político-administrativos e a comunidade através das entidades civis. Surge então o ambientalismo com todas suas virtudes e defeitos, como ação concreta na promoção e defesa do meio ambiente. Este movimento no Brasil ainda é setorizado, como também o é internacionalmente, mas existem aqui, fortes correntes para torná-lo abrangente, através da criação de mecanismo para sua coordenação. Cabe ressaltar ainda neste processo, o papel dos meios de comunicação que contribuem para divulgar, com grande amplitude, a questão ambiental.

Nas ações sobre o meio ambiente existem algumas confusões quanto ao uso do conceito ambientalismo e ecologia que são 
usados indistintamente. $\mathrm{O}$ primeiro se caracteriza como defesa e promoção das relações ambientais e deve ser balizado por fundamentação técnico-científica, enquanto o segundo é uma ciência e como tal funciona como instrumento científico da ação. E necessário que ambos os conceitos sejam utilizados em seus reais significados em nome da verdade científica, e não de forma demagógica como produto de consumo.

\section{SOBRE O CONCEITO DE MEIO AMBIENTE}

Em OLIVEIRA et alii (1976) aparece o meio ambiente com o sentido de organização, sendo o espaço seu suporte. Neste caso o espaço é material e representa um estado de relação em decorrência da organização dos componentes ambientais. E também hierarquizado, pois parte-se do macroespaço com o sistema global representado pela terra em sua totalidade; tendo a seguir o microespaço, onde estão presentes os menores estados de relação.

Os componentes do meio ambiente são diversos e podem ser classificados em abió- ticos, bióticos e bióticos-abióticos. Abióticos ou inorgânicos são o embasamento geológico, o relevo e o clima. Bióticos ou orgânicos são a flora e a fauna, incluindo o homem em decorrência da abrangência do sistema global. Cabe ainda ressaltar a existência de um componente intermediário, biótico-abiótico, o solo, praticamente a base da vida junto com a água. São os dois que dão suporte à vida integral e por sua vez à vida animal, originando assim a cadeia alimentar com toda a sua complexidade. $\mathrm{O}$ homem em decorrência da magnitude de sua ação condiciona arranjos próprios chamados de culturais (fig. 3) que dependem dos componentes sócio-econômicos. Sua introdução como um agente individualizado mostra ser ele, simultaneamente, um componente biótico e cultural.

\section{O MEIO AMBIENTE COMO SISTEMA}

Através da abordagem de sistemas é possível comprender melhor o funcionamento do meio ambiente, sendo necessário para esta finalidade usar a linguagem exemplificada no quadro abaixo:

\begin{tabular}{|c|c|c|}
\hline in put & feedback & out put \\
\hline energias & $\begin{array}{l}\text { interação de } \\
\text { componentes } \\
\text { usos múltiplos }\end{array}$ & $\begin{array}{c}\text { vulnerabilidade } \\
\text { impactos }\end{array}$ \\
\hline
\end{tabular}

Os "in puts" são as entradas de energia de várias ordens no sistema: solar, geotérmica, gravitacional, criada pelo homem, ou outras formas de energia. Essa energia condiciona processos que são os "feedbacks". No caso do sistema ambiental os feedbacks são as interações dos componentes do sistema, na forma de cadeia de elementos móveis que se formam através de processos de gênese e evolução, arranjos e rearranjos no espaço e no tempo. Isto expressa basicamente a qualidade dinâmica do sistema. Os usos múltiplos que o homem exerce, também fazem parte desses "feedbacks".
Os "out puts" ou saídas são as resultantes desse dinamismo e aparecem sob a forma de estados de vulnerabilidade, refletindo um potencial auto-regulado de mecanismos ambientais. Os impactos são "out puts" derivados dos usos múltiplos e se exercem em direção da vulnerabilidade ambiental. Quando forem maiores que a vulnerabilidade do ambiente, as respostas obtidas são negativas, pois o sistema se vê alterado criando novos arranjos para se ajustar ao balanço de energia e matéria. Surgem então novos sistemas que nem sempre são benéficos ao homem. 


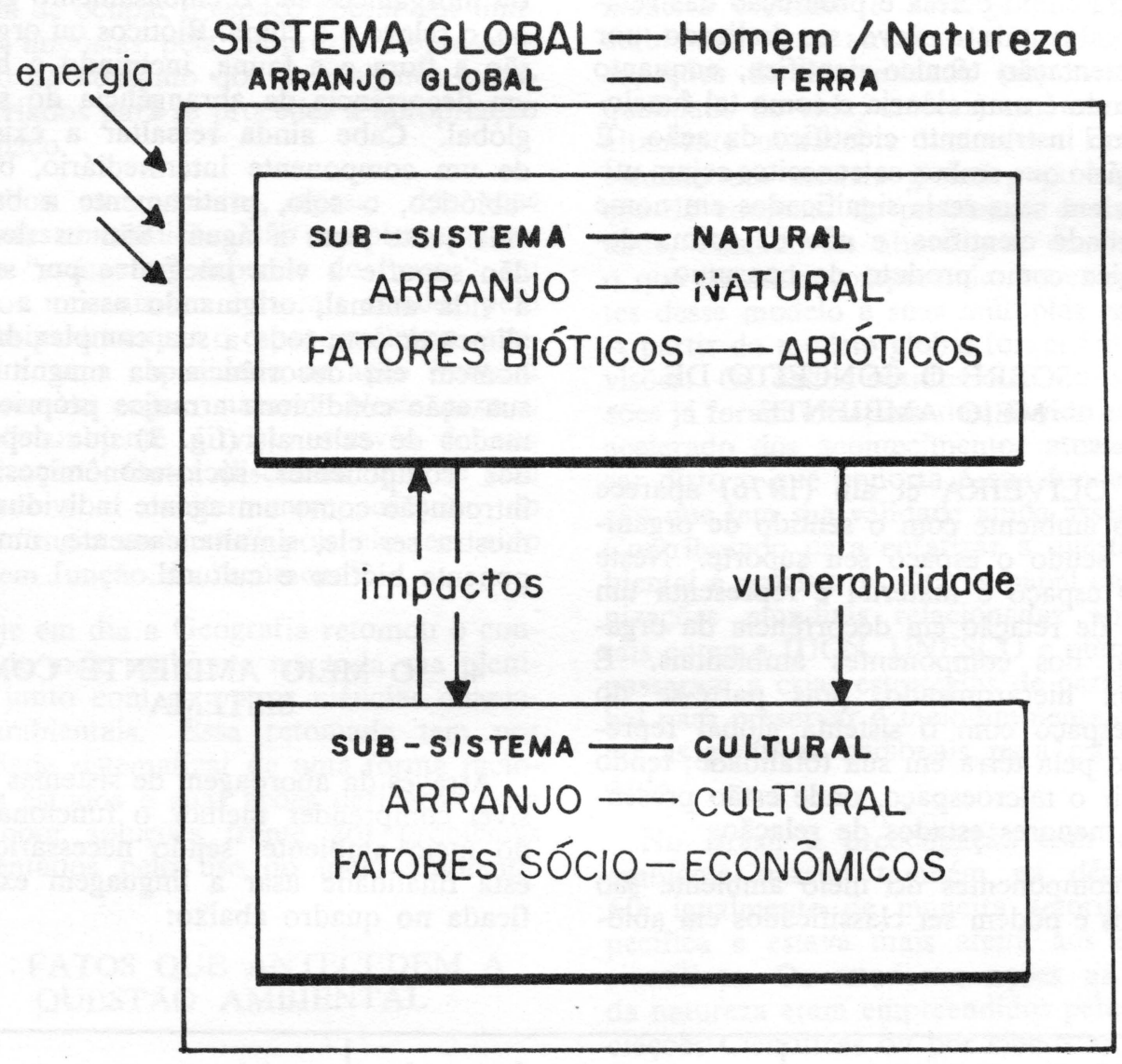

FIGURA 3

O sistema ambiental sendo hierarquizado é composto de subsistemas que representam unidades (fig. 1) onde estão expressas as relações de entrada de energia e seu fluxo, como ocorre no sistema global. Quando os arranjos da natureza dominam essas unidades tem-se o ecossistema, quando o homem é o componente dominante de um subsistema, a unidade passa a ser o geossistema.

As várias relações expressas pelo sistema ambiental condicionam qualidades estruturais e dinâmicas. A primeira se refere ao estado do sistema em dado momento no espaço, enquanto a segunda, ao processo de relação entre os componentes ambientais no tempo. Quando existe um estado de equilíbrio, onde os impactos são proporcionais à vulnerabilidade tem-se o "equilíbrio natural dinâmico".

As relações citadas condicionam ainda um potencial que pode ser especificamente, capacidade de produção de vida, e a capacidade de carga sobre determinado espaço.
A capacidade de produção de vida ou de biomassa está ligada à cadeia alimentar. $\mathrm{O}$ funcionamento dessa cadeia depende da quantidade de energia e matéria existentes no sistema. Quanto maior for a quantidade de energia e matéria disponível, maior será a complexidade e a quantidade de formas de vida dentro da cadeia alimentar. Tem-se neste caso uma grande capacidade de produção de biomassa. E o exemplo típico das regiões de florestas tropicais úmidas, onde a energia solar se faz presente com grande intensidade, aliado à existência de água e solo. Nessas regiões existe uma inimaginável riqueza de formas de vida e, por isso, são consideradas como banco genético. A capacidade de carga depende da qualidade estrutural e dinâmica do sistema delimitando a ação do homem quando ela se exerce no sentido espacial.

As características que toma o sistema ambiental dependem dos arranjos estruturais e são mostradas no seguinte quadro: 


\begin{tabular}{|c|c|c|c|}
\hline $\begin{array}{c}\text { ARRANJOS } \\
\text { ESTRUTURAIS }\end{array}$ & GLOBAL & NATURAL & CULTURAL \\
\hline REFERENCIAIS & TERRA & NATUREZA & HOMEM \\
\hline
\end{tabular}

Atualmente a ação humana assumiu tal magnitude que seu impacto é responsável por grande parte do desarranjo do sistema global. Assim, o dano ao meio ambiente é consequiência da intervenção intensa, aleatória e não planejada, superior à vulnerabilidade ambiental.

\section{OS RECURSOS DO MEIO AMBIENTE}

Através da análise do sistema ambiental nota-se que a energia condiciona mecanismos, que se exercem sobre componentes desse sistema expressos através da matéria, criando arranjos (fig. 1). A trilogia formada por energia, mecanismos e matéria representa os recursos do meio ambiente. (fig. 2).

O sol é a maior fonte do recurso energético que atinge a Terra. O clima sendo um mecanismo depende em grande parte da ação energética do sol, e se torna vital ao homem, pois condiciona a situação de "ecúmeno" ou seja, a capacidade, já citada, de o homem ocupar o espaço terrestre.

O uso do recurso ambiental depende da sua maior ou menor disponibilidade. No caso da energia solar a disponibilidade é de tal ordem que a torna inesgotável. No entanto um mecanismo como o clima pode ter seu uso restrito em decorrência de sua alteração. O homem pode alterar o clima de forma drástica, acarretando prejuízos para si. As grandes cidades são formas de ocupação humana que produzem modificações climáticas locais e até regionais que se têm evidenciado, marcantes e desfavoráveis.

Os recursos representados pela matéria podem ser classificados em renováveis e não renováveis. Os primeiros são aqueles relacionados aos ciclos naturais que dependem do potencial de reciclagem do sistema am- biental, são: água, relacionada ao ciclo hidrológico; a vegetação, que depende não só desse ciclo, mas também da matéria incorporada; a fauna, que depende da água e da vegetação. No entanto, o uso intensivo desses recursos pode torná-los não renováveis, é o caso da água em determinado espaço, pois sua reciclagem depende de mecanismos climáticos, que se alterados condicionam aí a diminuição da quantidade de água. Já a vida em forma de espécies pode ser perdida irremediavelmente.

Os recursos não renováveis ao serem utilizados, transformam-se de tal maneira impossibilitando seu uso novamente. Não dependem do ciclo da matéria de curto prazo, mas do potencial de reciclagem a longo prazo, numa escala de tempo de milhões, a milhares de anos. É o caso do solo e de alguns minerais como o ferro e o alumínio.

Alguns recursos são esgotáveis, pois foram formados em condições tais, que não se reproduzem mais na Terra. Estão fora da capacidade de reciclagem do sistema ambiental. Seu uso, os torna perdidos para sempre, como exemplo: o petróleo, o carvão vegetal.

\section{O ARRANJO CULTURAL}

O sistema global, homem/natureza (fig. 3) demonstra a existência da contraposição de dois subsistemas que se interagem através de trocas, condicionadas por vulnerabilidade e impactos. O último decorre da organização do subsistema cultural onde o ser humano organizado em sociedade exerce atividades econômicas que produzem impactos sobre o outro subsistema, o natural.

A ação humana sobre determinado espaço altera de forma marcante, as relações aí existentes. Destaca-se como exemplo a substituição de uma cobertura vegetal na- 
tural, como a floresta, por outra cultivada através da atividade agrícola. Nas cidades muitas vezes há a substituição completa da cobertura vegetal pelo piso sólido, asfalto, construções etc. É o caso das áreas centrais de São Paulo e de outras grandes cidades brasileiras. No primeiro caso a perda da vegetação acarreta um aumento de impacto da água sobre o solo com a perda desse pela erosão. A consequiência da perda do solo é a diminuição de sua fertilidade com reflexos na capacidade de produção de biomassa. No segundo caso ocorre a impermeabilização total da área, provocando a quebra do ciclo hidrológico, tendo como conseqüências enchentes etc., acarretando prejuízos ao subsistema cultural.

A ação do homem pode colocar em risco as condições de continuidade do sistema ambiental. O solo que levou milhares de anos para se formar, pode se perder em questão de poucas horas quando deixado por exemplo, exposto à ação da água. A recuperação do sistema ambiental, só começará a aparecer, após vários anos. O custo dessa recuperação é alto.
Quando o homem ao implantar suas atividades, respeita o potencial do sistema ambiental, optando por usos adaptados à capacidade de produção de biomassa e de carga, diz-se que existe um "equilíbrio cultural dinâmico". Neste caso o componente humano está equilibrado com os demais componentes do meio ambiente.

O manejo do meio ambiente representa uma atitude racional, intencional e planejada. E ainda uma ação cultural que reflete a necessidade de usar o meio ambiente implantando atividades que lhe são extemporâneas. Sendo a organização em sociedade uma das características humanas, essa organização assume aspectos extremamente complexos gerando a necessidade de atuar de uma forma igualmente complexa e eficiente para garantir a continuidade do sistema ambiental no futuro. Cabe aos planejadores propor ações abrangentes e globais que respeitem as relações básicas do meio ambiente. Assim será possível criar condições para que a humanidade possa sobreviver, convivendo de maneira harmoniosa com outras formas de vida.

\section{REFERÊNCIAS BIBLIOGRĀFICAS}

ALLEN, R. - 1980 - How to save the world Strategy for world conservation. London, Kogan Page. 150p.

BERTRAND, G. - 1972 - La science du paysage, une science diagonale. Révue Géographique des Pyrennées et du Sud-Ouest, Toulouse, 43(2):127-132.

DEMEK, J. - 1978 - The landscape as a geosystem. Geoforum, Oxford, 9(1):29-34.

KLINK, H.J. 1974 - Geoecology and natural regionalisation: bases for environmental research. Applied Science and Development, Tübingen, 4:48-74.

MEADOWS, D.H. et alii - 1973 - Limites do crescimento: um relatório para o projeto do Clube de Roma sobre o dilema da humanidade. São Paulo, Editora Perspectiva. 203p. (Coleção Debates, 90)

OLIVEIRA, M.C. et alii - 1976 - A natureza e o homem no Estado de São Paulo: um panorama. São Paulo, Sociedade Brasileira de Paisagismo. 49fls.
OLIVEIRA, M.C. et alii - 1982 - Política de ciência e tecnologia em geociências - Aproximação I. Revista do Instituto Geológico, São Paulo, 3(2):5-22, jul./dez.

RIBEIRO, A.G. - 1974 - A geografia, seu objeto e o meio ambiente. São Paulo, Universidade, Instituto de Geografia. $10 \mathrm{p}$. (Caderno de ciências da terra, 51)

SCHREIBER, K.F. - 1977 - Landscape planning and protection of the environment. Applied Sciences and Development, Tübingen, 9:128-139.

SOTCHAVA, V.B. - 1977 - O estudo de geosistemas. São Paulo, Universidade, Instituto de Geografia. 52p. (Métodos em questão, 16)

VIERS, G. - 1972 - Géographie physique, écologie et géographie zonale. Révue Géographique des Pyrenées et du Sud-Ouest. Toulouse, 43(2):143-146.

ZONNEVELD, I.S. - 1982 - The ecosciences in resource and environmental surveys. ITC Journal, Enschede, (1):17-18. [Special 30th anniversary issue] 